\title{
Anterior Approach Following Intraoperative Reduction for Cervical Facet Fracture and Dislocation
}

\author{
Seul Gi Kim, Seon Joo Park, ${ }^{2}$ Hui Sun Wang, ${ }^{1}$ Chang Il Ju, ${ }^{1}$ Sung Myung Lee, Seok Won Kim ${ }^{1}$ \\ Department of Neurosurgery,' College of Medicine, Chosun University, Gwangju, Korea \\ Department of Natural Medical Sciences, ${ }^{2}$ College of Medicine, Chosun University, Gwangju, Korea
}

Objective : The purpose of this study was to evaluate the efficacy of the anterior approach following intraoperative reduction under general anesthesia in patients with cervical facet fracture and dislocation.

Methods : Twenty-three patients with single level cervical facet fracture and dislocation who were subjected to the anterior approach alone following immediate intraoperative reduction under general anesthesia from March 2013 to December 2017 were enrolled in this study. Neurological status, clinical outcome, and radiological studies were evaluated preoperatively, postoperatively, and during the follow-up period.

Results : The cohort comprised 15 men and eight women with a mean age of 57 years (from 24 to 81 ). All patients were operated on within the first 8 hours following the injury. After gentle manual reduction or closed reduction with Gardner-Wells traction, under general anesthesia monitored by somatosensory-evoked potentials, all operations were successfully completed using the anterior approach alone except in two patients, who had a risk of over-distraction. In them, a satisfactory gentle manual reduction or closed reduction was not possible, and required open posterior reduction of the locked facets followed by anterior cervical discectomy and fusion. In one patient, screw retropulsion was observed in 1 month after surgery. There were no reduction-related complications or neurological aggravations after surgery. All patients showed evidence of stability at the instrumented level at the final follow-up (mean follow-up, 12 months).

Conclusion : Anterior approach following intraoperative reduction monitored by somatosensory-evoked potentials under general anesthesia for cervical dislocation and locked facets is a relatively safe and effective alternative when cervical alignment is achieved by intraoperative reduction.

Key Words : Cervical vertebra · Fracture dislocation.

\section{INTRODUCTION}

Traumatic cervical spine fracture and dislocation, one of the most common devastating injuries involving the axial skeleton may be accompanied by direct spinal cord or nerve root injury ${ }^{5)}$. However, due to the risk of iatrogenic damage of the neurological function by over-distraction, global standards for the treatment strategy are not currently available.

- Received : June 11, 2019 •Revised : July 23, 2019 •Accepted : August 5, 2019

- Address for reprints : Seok Won Kim

Department of Neurosurgery, College of Medicine, Chosun University, 365 Pilmun-daero, Dong-gu, Gwangju 61453, Korea

Tel : +82-62-220-3126, Fax : +82-62-227-4575, E-mail : chosunns@chosun.ac.kr, ORCID : https://orcid.org/0000-0002-1910-0242

This is an Open Access article distributed under the terms of the Creative Commons Attribution Non-Commercial License (http://creativecommons.org/licenses/by-nc/4.0) which permits unrestricted non-commercial use, distribution, and reproduction in any medium, provided the original work is properly cited. 
The surgeon's experience in surgical approaches such as closed reduction in awake patients, gentle manual reduction under general anesthesia or open reduction, anterior or posterior approach or both is the main decision factor. Moreover, it is well known that the reduction process itself could aggravate the spinal cord injury, especially in patients with herniated disc or broken disc displacement ${ }^{7,9,15)}$.

In the literature, it is suggested that the posterior approach is necessary in cases with unreducible dislocation, but it is accompanied by risks of excessive muscle dissection, postoperative pain, blood loss, and difficulties in maintaining safe vital signs in the prone position ${ }^{12,13)}$. On the contrary, the anterior approach with decompression and stabilization reduces the risk of catastrophic neurological sequelae and complications. Furthermore, the anterior approach provides the opportunity to treat only one motion segment by fusion and instrumentation compared with the common practice of fusing two motion segments in posterior approaches, if good realignment is achieved $^{1,4)}$.

In this study, we report the results of the retrospective analysis of patients with cervical fracture and dislocation that tried intraoperative reduction under general anesthesia followed by the anterior approach alone.

\section{MATERIALS AND METHODS}

This study was approved by the Institutional Review Bord of Chosun University Hospital, which waved the requirement for informed consent due to the respective nature of study. We studied cases of cervical fracture and dislocation in which we performed intraoperative reduction under general anesthesia followed by anterior reconstruction, during a 5-year period (from March 2013 to December 2017). The inclusion criteria comprised single-level unilateral or bilateral cervical facet fracture and dislocation without concomitant prominent vertebral fractures.

Patients with relevant accompanying traumatic brain injury, unstable vital sign by multiple severe trauma or alcohol intoxication were excluded from the study. All surgeries were performed by same surgeon, i.e., the corresponding author. Twenty-three patients, 15 men and 8 women aged 24-81 years (mean, 57) with traumatic fracture and dislocation of the cervical spine were included in the study. The most common cause of injury was motor vehicle accident (16 cases, 70\%). Plain radiographs and cervical computed tomography including 3-dimensional reconstruction were performed in all patients, but preoperative magnetic resonance imaging (MRI) was not routinely performed due to the risk of delayed reduction or aggravation of the neurological function. Imaging studies revealed fracture and dislocation of the cervical spine at C3-4 in three, C4-5 in three, C5-6 in nine, C6-7 in seven patients, and $\mathrm{C} 7-\mathrm{T} 1$ in one patient. All patients were operated within 8 hours after injury.

\section{Monitoring of spinal cord evoked potential}

Channel 32 spinal cord evoked potential monitoring instrument (NIM 3.0 ECILIPSE nerve monitoring system; Medtronic, New York, NY, USA) was used and monitored by neurologist. The combined monitoring strategy consists of cortical sensory evoked potential (CSEP) and transcranial electrical stimulation motor evoked potential (TES-MEP) recording. Continuous intraoperative CSEP monitoring was observed, but TES-MEP was recorded intermittently combined with CSEP.

\section{Surgical technique}

After sufficient explanation of the procedure related risks, gentle manual reduction or cranio-cervical traction was performed under general anesthesia in the operating room. Anesthesia was maintained without the application of muscle relaxants as little as possible and inhalation agents, are more potent suppressants of evoked potential than intravenous agents, intravenous anesthesia was employed. Upon general anesthesia, with simultaneous monitoring of the somatosensory evoked potentials, gentle manual reduction of the locked cervical facets was attempted, initially by a gentle manual torsion with neck flexion and rotation toward the contralateral side of the dislocation, followed by rotation toward the side of dislocation, and, finally, head extension.

In cases where good realignment by careful manual reduction was achieved, a standard Smith-Robinson anterior approach was used for spinal reconstruction. Gardner-Wells tongs were applied when realignment was not achieved by gentle manual reduction and were placed at points located 1 $\mathrm{cm}$ behind and $2.5 \mathrm{~cm}$ above the external auditory canal. The initial traction weight was $2 \mathrm{~kg}$ and was increased progressively. To avoid over-distraction, C-arm fluoroscopy was used to 
observe the reduction process.

Once the patients were re-aligned, all of them underwent anterior surgery, with anterior discectomy, interbody fusion with cage, and anterior cervical plating. If the alignment was not successful after closed maneuvers, an open posterior reduction was performed followed by the anterior approach.

All patients wore a Philadelphia collar for 12 weeks postoperatively and underwent a follow-up examination, in which they were subjected to an early postoperative cervical X-ray serial. The successful fusion criteria was defined as bridging trabecular bone and absence of a radiolucent gap between the graft and end plate or absence of more than $2 \mathrm{~mm}$ on flexion and extension views. All patients were followed-up for an average of 12 months (5 to 24 months).

\section{Statistical analysis}

We reviewed the patients' charts for data including the cause of injury and the level of neurological function determined by the American Spinal Injury Association (ASIA) impairment scale on admission and during follow-up examination.

The relevant neck pain was recorded according to the visual
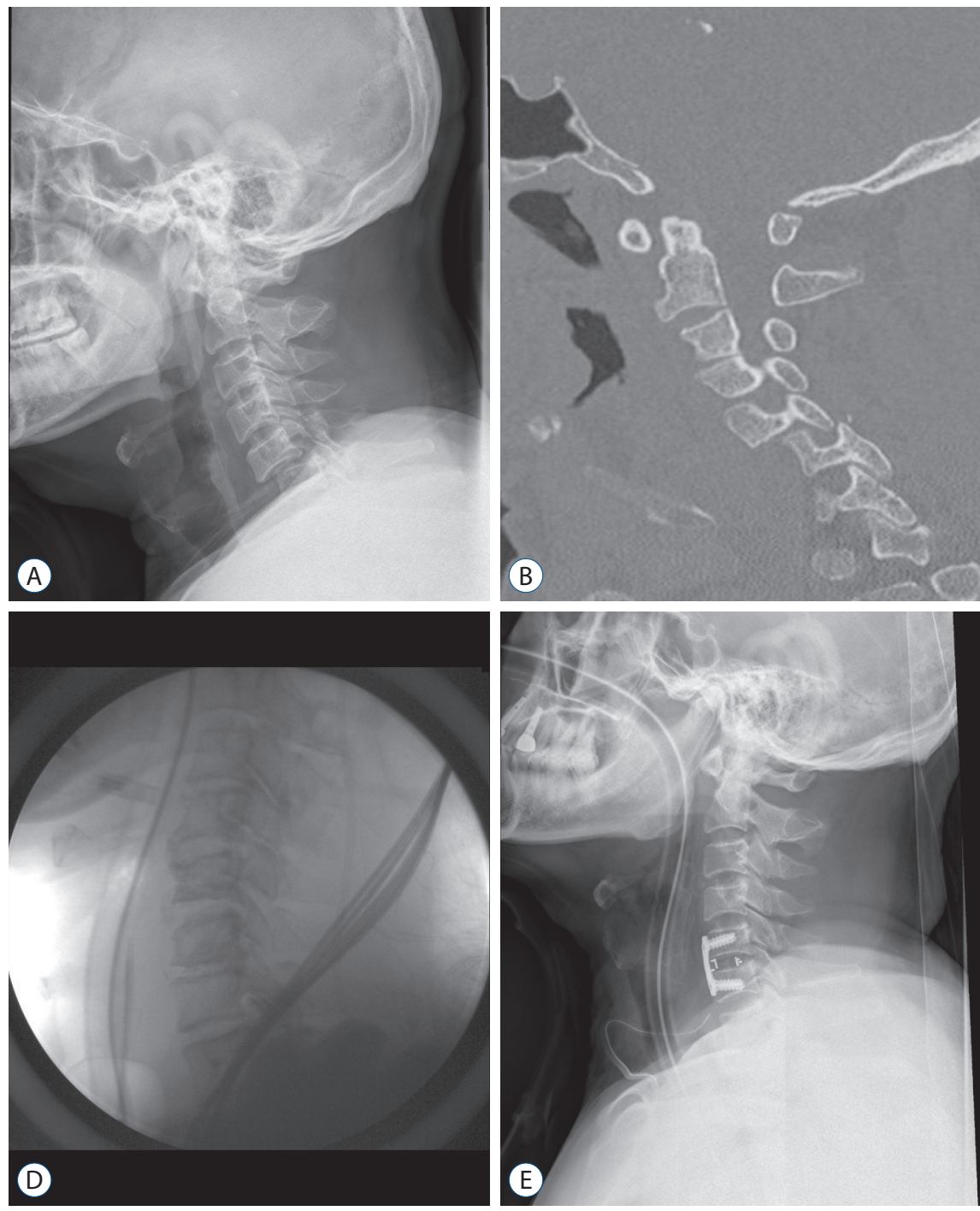
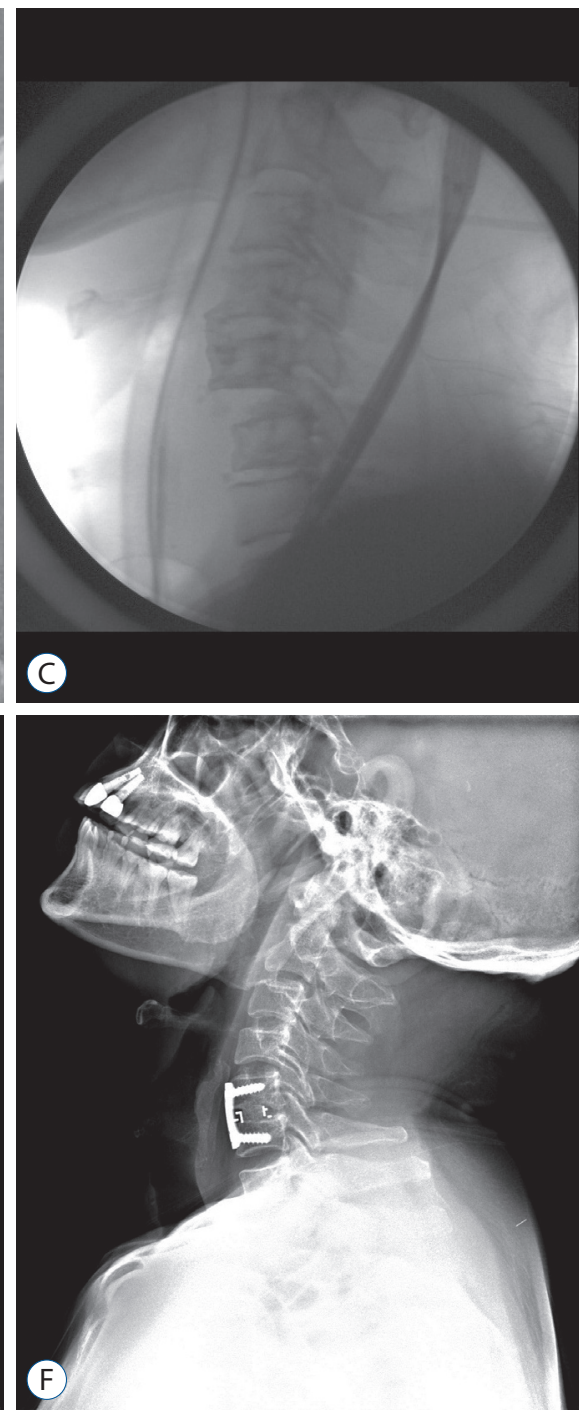

Fig. 1. Representative images of a 45-year-old male patient. A : Simple lateral cervical radiograph demonstrates facet dislocation of C5-C6. B : Preoperative computed tomography scan shows facet interlocking at C5-C6 level. C and D: Good alignment is achieved after intraoperative manual reduction under general anesthesia. E : Postoperative lateral cervical radiograph shows good alignment after application of the anterior approach alone. F : Good alignment is still maintained after 12 months. 
analogue scale (VAS) score preoperatively, postoperatively, at 3 months after surgery, and at the final follow-up. Student's $t$ test was used for comparison between groups in the SPSS 17.0 software (SPSS Inc, Chicago, IL, USA), and a $p$ value $<0.05$ was considered as statistically significant.

\section{RESULTS}

Twenty-three patients with single level fracture and dislocation of the cervical spine who underwent intraoperative reduction under general anesthesia and anterior spinal reconstruction were identified during a 5-year period (15 men, eight women; mean age of 57 years, from 24 to 81). In most patients, correct alignment was achieved under general anesthesia monitored by spinal cord evoked potential. Thirteen patients were completely reduced by gentle manual reduction, and eight patients were subjected to closed reduction using Gardner-Wells traction performed with a mean weight of $10 \mathrm{~kg}$, ranging from 8 to $12 \mathrm{~kg}$. There were no fractures and aggravated neurologic deficits caused by the gentle manual reduction or closed craniocervical traction. During the process of manual reduction, traction or anterior approach in most patients, CSEP latency amplitude showed improvement and TES-MEP demonstrated no change (21 patients). These patients underwent anterior discectomy, interbody fusion with cage, and anterior cervical plate insertion (Fig. 1).

In two patients, when the traction weight was $8 \mathrm{~kg}$ and 12 $\mathrm{kg}$ respectively, whose CSEP dropped by 65\% with ware form transforming, there was a risk of over-distraction and a satisfactory closed reduction was not possible. Therefore, they were firstly subjected to open reduction by posterior approach followed by an anterior approach with discectomy and cage insertion (Fig. 2). In another patient, in whom good re-alignment was achieved by gentle manual reduction, screw retropulsion was observed 1 month after anterior fusion and plate insertion, and screw repositioning via the anterior approach was required. There were no surgery-related complications. Fusion was achieved in all patients as evidenced in the final follow-up except for one patient who died 5 months after surgery due to acute myocardial infarction.

Although some patients complained of remained neck discomfort and neck stiffness, a statistically significant difference between their VAS scores at the 3 months follow-up and final follow-up was recorded. None of the patients demonstrated aggravated ASIA score after the operation (Table 1).

\section{DISCUSSION}

Facet fracture and dislocation of the cervical spine is a severe traumatic lesion usually accompanied by both anterior
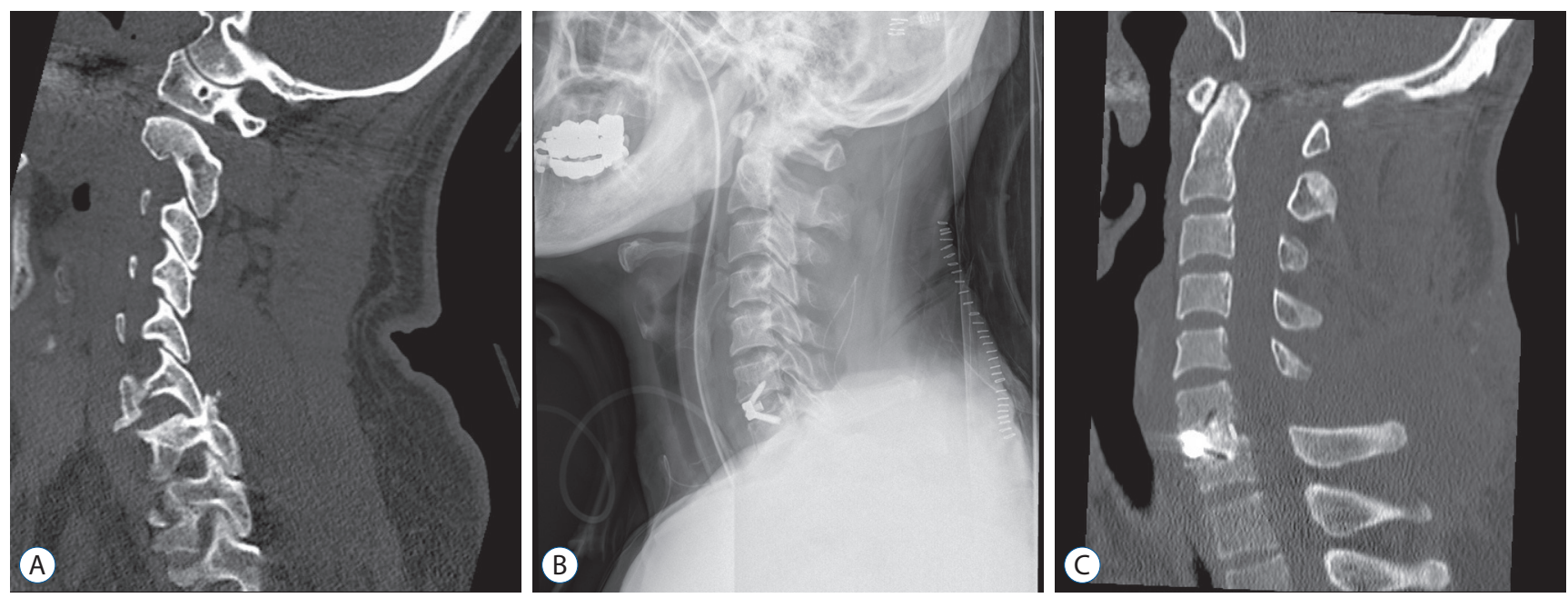

Fig. 2. Representative images of a 57-year-old male patient. A : Preoperative computed tomography scan shows facet interlocking at C6-C7 level. B : Postoperative lateral cervical radiograph shows good alignment after intraoperative reduction under general anesthesia using posterior open reduction followed by the anterior discectomy and fusion. C: Postoperative computed tomography scan at 8 months after surgery reveals trabecular bone bridging and maintained good alignment. 
Table 1. Demographic data of the enrolled patients

\begin{tabular}{|c|c|c|c|c|c|c|c|c|}
\hline Case & Age/sex & $\begin{array}{l}\text { Involved } \\
\text { level }\end{array}$ & $\begin{array}{l}\text { Unilateral/ } \\
\text { bilateral }\end{array}$ & $\begin{array}{c}\text { Preoperative } \\
\text { MRI }\end{array}$ & $\begin{array}{l}\text { Time from injury to } \\
\text { surgery (hours) }\end{array}$ & Traction & $\begin{array}{c}\text { ASIA scalepreop/ } \\
\text { final F/U }\end{array}$ & Remarks \\
\hline 1 & $57 / \mathrm{M}$ & $\mathrm{C} 6 / \mathrm{C} 7$ & Bilateral & No & 8 & Yes & $E / E$ & Open reduction \\
\hline 2 & $45 / \mathrm{M}$ & C5/C6 & Bilateral & Yes & 6 & No & $\mathrm{B} / \mathrm{C}$ & \\
\hline 3 & $43 / F$ & $\mathrm{C} 7 / \mathrm{T} 1$ & Unilateral & No & 6 & No & E/E & \\
\hline 4 & $48 / M$ & $\mathrm{C} 3 / \mathrm{C} 4$ & Unilateral & Yes & 4 & Yes & $C / D$ & \\
\hline 5 & $49 / F$ & $\mathrm{C} 5 / \mathrm{C6}$ & Unilateral & No & 5 & No & $E / E$ & \\
\hline 6 & $75 / \mathrm{M}$ & $\mathrm{C6} / \mathrm{C} 7$ & Unilateral & No & 8 & No & $\mathrm{D} / \mathrm{E}$ & \\
\hline 7 & $76 / F$ & $\mathrm{C} 3 / \mathrm{C} 4$ & Bilateral & Yes & 7 & Yes & $E / E$ & \\
\hline 8 & $67 / M$ & $\mathrm{C} 6 / \mathrm{C7}$ & Bilateral & Yes & 8 & No & $A / B$ & \\
\hline 9 & $52 / \mathrm{M}$ & $\mathrm{C} 5 / \mathrm{C6}$ & Unilateral & Yes & 8 & No & $B / C$ & $\begin{array}{l}\text { Ankylosing } \\
\text { spondylitis }\end{array}$ \\
\hline 10 & $45 / F$ & $\mathrm{C} 5 / \mathrm{C} 6$ & Unilateral & No & 4 & Yes & $E / E$ & \\
\hline 11 & $30 / \mathrm{M}$ & $\mathrm{C} 6 / \mathrm{C} 7$ & Unilateral & No & 5 & No & $E / E$ & \\
\hline 12 & $42 / F$ & $\mathrm{C6/C7}$ & Bilateral & No & 6 & No & $E / E$ & \\
\hline 13 & $73 / \mathrm{M}$ & $\mathrm{C6/C7}$ & Bilateral & No & 6 & No & $E / E$ & \\
\hline 14 & $81 / F$ & $\mathrm{C} 5 / \mathrm{C} 6$ & Bilateral & Yes & 6 & Yes & $B / C$ & \\
\hline 15 & $63 / \mathrm{M}$ & $\mathrm{C6} / \mathrm{C7}$ & Bilateral & No & 8 & No & $\mathrm{D} / \mathrm{E}$ & \\
\hline 16 & $57 / M$ & $\mathrm{C} 4 / \mathrm{C} 5$ & Unilateral & No & 5 & No & $\mathrm{D} / \mathrm{E}$ & \\
\hline 17 & $64 / M$ & $C 4 / C 5$ & Bilateral & No & 5 & Yes & $E / E$ & \\
\hline 18 & $54 / M$ & $\mathrm{C} 5 / \mathrm{C} 6$ & Unilateral & No & 8 & Yes & $B / C$ & Open reduction \\
\hline 19 & $68 / M$ & $\mathrm{C} 5 / \mathrm{C} 6$ & Unilateral & No & 7 & No & $C / E$ & \\
\hline 20 & $24 / F$ & $\mathrm{C} 3 / \mathrm{C} 4$ & Bilateral & Yes & 7 & No & $C / D$ & \\
\hline 21 & 75/M & $\mathrm{C} 5 / \mathrm{C} 6$ & Unilateral & Yes & 6 & No & $\mathrm{B} / \mathrm{C}$ & $\begin{array}{l}\text { Screw } \\
\text { retropulsion }\end{array}$ \\
\hline 22 & $77 / \mathrm{M}$ & $\mathrm{C} 5 / \mathrm{C} 6$ & Unilateral & Yes & 8 & No & $A / B$ & Died of Ml \\
\hline 23 & $46 / F$ & C4/C5 & Bilateral & No & 8 & Yes & $E / E$ & \\
\hline
\end{tabular}

MRI : magnetic resonance imaging, ASIA : American Spinal Injury Association, F/U : follow up, M : male, F : female, MI : myocardial infarction

and posterior discoligamentous instability ${ }^{15,21)}$. The eventual goals of surgical treatment of facet fracture and dislocation include the return to functional ability, minimum neurological deficits, minimum residual deformity, and prevention of further disability ${ }^{23)}$.

Facet fracture and dislocation of the cervical spine usually result from flexion-rotation injury and can cause facet interlocking in the dislocated position by the inferior articular facet of the upper vertebra overriding the superior articular facet of the lower vertebra ${ }^{19)}$. The dislocated facet is generally not able to return to its normal position without manipulation, open or closed reduction, and surgery ${ }^{22)}$. Reduction per se is beneficial as a simple stabilization procedure and is also the best decompression method. Apparently, the quicker the adequate reduction, the more successful alignment and decompression are achieved by eliminating bony compression of the spinal cord. O'Connor et al. ${ }^{18)}$ reported 21 patients with cervical facet injuries treated with attempted craniocervical traction. Good realignment was achieved in 11 patients, but it was not successful in cases where closed reduction was applied later than 5 days after injury.

The most common form of reduction has been the closed reduction with skull tongs immediately after injury on awake patients, with administration of muscle relaxants, reserving open reduction as an alternative in cases of failed closed reduction $^{20)}$. However, closed reduction in the awake state has several drawbacks. First of all, it fails in a substantial percentage of patients, and requires burdened traction weights. Sec- 
ond, closed reduction exposes the patient with trauma to supplementary immobilization and severe pain ${ }^{13)}$.

On the other hand, the studies by Kleyn ${ }^{11}$ have popularized the method of reduction under general anesthesia, although other authors criticize this procedure as potentially dangerous compared to reduction by craniocervical traction in awaken status. Manipulation under general anesthesia has been a common technique, often applied following failure of traction-induced reduction but only occasionally used as a primary procedure for achieving reduction ${ }^{11,24)}$. Patients with fracture/dislocation often have associated herniated discs that cause ventral cord compression at the level of injury either as a result of the injury itself or as an iatrogenic effect of manual closed reduction despite the use of an image intensifier to minimize over-distraction ${ }^{17)}$. Reports of neurological aggravation by disc material compressing spinal cord following closed or open reduction has led some authors to recommend the use of pre-reduction MRI to identify ventral cord compression potentially caused by traumatic disc herniation. However, prereduction MRI requires movement of a patient with a potentially unstable cervical spinal fracture/dislocation injury to the MRI room. In addition, the use of pre-reduction MRI may delay the procedure for the reduction of the spinal deformity and therefore is bound to delay decompression of the spinal cord. Moreover, although pre-reduction MRI can demonstrate traumatic disc herniation and cord compression, the clinical significance of these findings is uncertain. Only a few reports have demonstrated that neurological deterioration resulted from disc herniation following a satisfactory closed craniocervical reduction ${ }^{6,16)}$.

For these reasons, preoperative MRI was not routinely performed in our consecutive patients. None of the patients worsened following intraoperative reduction under general anesthesia with neurological monitoring using the somatosensory evoked potentials.

Shen et al. ${ }^{23)}$ reported 12 patients that underwent immediate reduction using Gardner-Wells tongs under general anesthesia and single-stage anterior and posterior spinal reconstruction for facet fracture and dislocation. Their procedure was similar to that described in the current report, the patients were reduced under general anesthesia and complete realignment and fusion was achieved in all patients, as verified during the final follow-up. In the current study, we tried immediate gentle manual or closed reduction using Gardner-Wells tongs un- der general anesthesia, simultaneously monitoring the somatosensory-evoked potentials. Only two patients, in whom reduction was incomplete and there was a risk of over-distraction, required open posterior reduction without lateral mass screw followed by anterior discectomy and fusion. The anterior fixation alone led to solid fusion in all patients except one patient who died of acute myocardial infarction.

In the past, fracture dislocation of the cervical spine used to be treated by conservative techniques such as immobilization using Halo rings or cervical collar ${ }^{2}$. However, conservative techniques usually fail. Failure rates with conservative therapy are up to $77 \%$; therefore, surgery is the gold standard approach for this pathology $y^{8)}$

Posterior open reduction and stabilization consists of a partial or complete facetectomy, reduction and dorsal screw fixation and fusion ${ }^{12}$. Doran et al..$^{3)}$ reported that posterior screw fixation might be biomechanically superior to a rigid anterior construct. Anatomically, direct decompression of the nerve roots is more completely accomplished through a posterior exposure, and there is a lower incidence of dysphagia. Moreover, reduction of the facets can be visually confirmed with the open posterior approach ${ }^{3)}$. However, the posterior approach is not without substantial risks. The incidence of neurological injury in open posterior approach may be greater than that reported previously ${ }^{10}$. Further, it is widely known that the posterior approach has an increased risk of infection compared with anterior approaches and prone position itself has difficulties in maintaining safe vital signs during operation, especially under traumatic conditions. In addition, some authors have reported that the posterior approach alone has the additional risk of anterior collapse of the disc, which may result in kyphosis ${ }^{14)}$. Furthermore, enough stability to achieve sufficient fusion rates may not be provided by the posterior approach alone, especially in cases that involve fractured inferior articular processes.

On the other hand, the anterior approach has some advantages including technical familiarity, short fusion construct and easy decompression of the spinal cord in cases accompanied by disc herniation. On the basis of our experience with the above described technique, we believe that the anterior approach following immediate intraoperative reduction under general anesthesia can be the first treatment option for cervical fracture and dislocation for the following reasons. First, general anesthesia with muscle relaxants is helpful to elimi- 
nate the apprehension and pain of the patient during the manual reduction or skull traction. Second, immediate reduction monitored by spinal cord evoked potentials and image intensifier can make the anterior approach safe, avoiding excessive traction-related injury of the spinal cord and iatrogenic damage of neurological function. Third, the anterior approach alone can provide not only immediate stability but also long term spinal stability, obviating the need for posterior screw fixation or external immobilization.

Despite the above-mentioned advantages of this technique, it is not without drawbacks. For patients with severe spinal cord injury involving entire 3-column structures, simultaneous anteroposterior surgery might be applicable and the anterior approach alone may be not recommended. Moreover, the strategy is not recommended for the patients with severe spinal cord injury. For cases of severe spinal cord injury, somatosensory or motor evoked potentials may not be monitored due to its substantial damage.

\section{CONCLUSION}

Intraoperative reduction under general anesthesia, monitored by spinal evoked potentials and followed by anterior spinal reconstruction can be performed rapidly, easily, and safely with no time loss or discomfort for the patient compared with closed reduction by traction in the awake status. It can be an effective alternative for cervical facet fracture and dislocation without entire three column injury and severe spinal cord injury.

\section{CONFLICTS OF INTEREST}

No potential conflict of interest relevant to this article was reported.

\section{INFORMED CONSENT}

Informed consent was obtained from all individual participants included in this study.

\section{AUTHOR CONTRIBUTIONS}

\author{
Conceptualization : SWK \\ Data curation : SGK, SJP \\ Formal analysis : HSW \\ Funding acquisition : $\mathrm{CIJ}$ \\ Methodology : SML, SWK \\ Project administration : SGK \\ Visualization : SGK, CIJ \\ Writing - original draft : SWK \\ Writing - review \& editing : SGK, SJP, SWK
}

\section{ORCID}

$\begin{array}{ll}\text { Seul Gi Kim } & \text { https://orcid.org/0000-0001-5002-3313 } \\ \text { Seon Joo Park } & \text { https://orcid.org/0000-0002-0498-572X } \\ \text { Hui Sun Wang } & \text { https://orcid.org/0000-0002-6401-2145 } \\ \text { Chang Il Ju } & \text { https://orcid.org/0000-0001-9123-2808 } \\ \text { Sung Myung Lee } & \text { https://orcid.org/0000-0003-1548-8435 } \\ \text { Seok Won Kim } & \text { https://orcid.org/0000-0002-1910-0242 }\end{array}$

\section{- Acknowledgements}

This study was supported by research fund from Chosun University Hospital, 2018.

\section{References}

1. Alexander $\mathrm{E} \mathrm{Jr}$, Davis $\mathrm{CH} \mathrm{Jr}$, Forsyth $\mathrm{HF}$ : Reduction and fusion of fracture dislocation of the cervical spine. J Neurosurg 27 : 588-591, 1967

2. Caspar W, Barbier DD, Klara PM : Anterior cervical fusion and caspar plate stabilization for cervical trauma. Neurosurgery $25:$ 491-502, 1989

3. Doran SE, Papadopoulos SM, Ducker TB, Lillehei KO : Magnetic resonance imaging documentation of coexistent traumatic locked facets of the cervical spine and disc herniation. J Neurosurg $79: 341-345,1993$

4. Du W, Wang C, Tan J, Shen B, Ni S, Zheng Y : Management of subaxial cervical facet dislocation through anterior approach monitored by spinal cord evoked potential. Spine (Phila Pa 1976) 39 : 48-52, 2014

5. Eismont FJ, Arena MJ, Green BA : Extrusion of an intervertebral disc associated with traumatic subluxation or dislocation of cervical facets. Case report. J Bone Joint Surg Am 73 : 1555-1560, 1991

6. Farmer J, Vaccaro A, Albert TJ, Malone S, Balderston RA, Cotler JM : Neurologic deterioration after cervical spinal cord injury. J Spinal Disord $11: 192-196,1998$ 
7. Feng G, Hong Y, Li L, Liu H, Pei F, Song Y, et al. : Anterior decompression and nonstructural bone grafting and posterior fixation for cervical facet dislocation with traumatic disc herniation. Spine (Phila Pa 1976) 37 : 2082-2088, 2012

8. Glaser JA, Whitehill R, Stamp WG, Jane JA : Complications associated with the halo-vest. A review of 245 cases. J Neurosurg 65 : 762-769, 1986

9. Hadley MN, Walters BC, Grabb PA, Oyesiku NM, Przybylski GJ, Resnick DK, et al. : Treatment of subaxial cervical spinal injuries. Neurosurgery 50 (3 Suppl) : S156-S165, 2002

10. Jónsson $H$ Jr, Cesarini $K$, Petrén-Mallmin $M$, Rauschning W : Locking screw-plate fixation of cervical spine fractures with and without ancillary posterior plating. Arch Orthop Trauma Surg 111 : 1-12, 1991

11. Kleyn PJ : Dislocations of the cervical spine: closed reduction under anaesthesia. Paraplegia 22 : 271-281, 1984

12. Lee $\mathrm{DH}$, Song GS : Analysis of posterior cervical fixation and fusion in subaxial cervical spine injury. J Korean Neurosurg Soc 30 : 13881393, 2001

13. Lee JY, Nassr A, Eck JC, Vaccaro AR : Controversies in the treatment of cervical spine dislocations. Spine J 9 : 418-423, 2009

14. Lifeso RM, Colucci MA : Anterior fusion for rotationally unstable cervical spine fractures. Spine (Phila Pa 1976) 25 : 2028-2034, 2000

15. Lu K, Lee TC, Chen HJ : Closed reduction of bilateral locked facets of the cervical spine under general anaesthesia. Acta Neurochir (Wien) 140 : 1055-1061, 1998

16. Maiman DJ, Barolat G, Larson SJ : Management of bilateral locked facets of the cervical spine. Neurosurgery 18 : 542-547, 1986

17. Maynard FM Jr, Bracken MB, Creasey G, Ditunno JF Jr, Donovan WH, Ducker TB, et al. : International standards for neurological and functional classification of spinal cord injury. American spinal injury association. Spinal Cord 35 : 266-274, 1997

18. O'Connor PA, McCormack O, Noël J, McCormack D, O'Byrne J : Anterior displacement correlates with neurological impairment in cervical facet dislocations. Int Orthop 27 : 190-193, 2003

19. Ordonez BJ, Benzel EC, Naderi S, Weller SJ : Cervical facet dislocation: techniques for ventral reduction and stabilization. J Neurosurg 92 (1 Suppl) : 18-23, 2000

20. Payer M, Schmidt MH : Management of traumatic bilateral locked facets of the subaxial cervical spine. Contemp Neurosurg $27:$ 1-3, 2005

21. Razack N, Green BA, Levi AD : The management of traumatic cervical bilateral facet fracture-dislocations with unicortical anterior plates. J Spinal Disord $13: 374-381,2000$

22. Scher AT : Unilateral locked facet in cervical spine injuries. AJR Am J Roentgenol 129 : 45-48, 1977

23. Shen $Y$, Shen $H L$, Feng ML, Zhang WB : Immediate reduction under general anesthesia and single-staged anteroposterior spinal reconstruction for fracture-dislocation of lower cervical spine. J Spinal Disord Tech $28: 1-8,2015$

24. Vital JM, Gille 0 , Sénégas J, Pointillart V : Reduction technique for uniand biarticular dislocations of the lower cervical spine. Spine (Phila Pa 1976) $23: 949-954,1998$ 